\title{
25th Anniversary of the TCM Hospital Bad Kötzting - Happy Birthday to You!
}

\author{
Dieter Melchart ${ }^{a, b}$ Jingzhang Daic,d \\ ${ }^{a}$ Competence Centre for Complementary Medicine and Naturopathy, Klinikum rechts der Isar, Technische Universität München, Munich, \\ Germany \\ b Institute for Complementary and Integrative Medicine, University Hospital Zurich and University of Zurich, Zurich, Switzerland \\ ${ }^{\mathrm{c}}$ TCM hospital Bad Kötzting, Bad Kötzting, Germany; ${ }^{\mathrm{d} B e i j i n g ~ U n i v e r s i t y ~ o f ~ C h i n e s e ~ M e d i c i n e, ~ B e i j i n g, ~ C h i n a ~}$
}

It is a great pleasure and honour for us to serve with an editorial on the occasion of the 25th anniversary of the Traditional Chinese Medicine hospital Bad Kötzting. The first German hospital for Traditional Chinese Medicine (TCM), established in 1991, is a wellrecognised and highly accepted hospital in central Europe, combining psychosomatic medicine and TCM. Dieter Melchart, editor of this supplement of FORSCHENDE KOMPLEMENTÄRMEDIZIN / RESEACH IN COMPLEMENTARY MEDICINE and first Director of the Centre of Complementary Medicine and Naturopathy (CoCoNat) in Munich, is head of the scientific board of the TCM hospital. He convoyed and influenced many designs and developments of the scientific work of the hospital, which evolved in this long period of time. The co-editor, Jingzhang Dai, from the Beijing University of Chinese Medicine, is medical director of the TCM medical team and therefore responsible for the health care activities. Dai is the most important person for the intercommunion and for the scientific as well as political exchange between hospital, scientific board and authorities such as universities, public institutions and associations in the People's Republic of China. The objective of the present issue of this supplement is to illustrate the most relevant cornerstones of the scientific activities of the TCM hospital Bad Kötzting.

The contribution of Dai et al. [1] gives insights into the infrastructure and medical processes of diagnostic and therapeutic interactions at the hospital. Weidenhammer and Melchart [2] show that an electronic documentation and systematic clinical audit system is feasible - even without recourse to special financial resources. The article presents preliminary information on patients treated, the diagnostic and therapeutic interventions provided, and patient-oriented outcomes obtained. Clinical outcomes and pragmatic studies are important scientific approaches to create a riskbenefit profile for TCM in everyday practice.

A further scientific priority of the TCM hospital Bad Kötzting is to conduct quality studies on identity, purity and content of ingre- dients of Chinese medicinal drugs used for inpatient treatment. Responsible for this area of interest are Hildebert Wagner of the Center for Drug Research of the Ludwig-Maximilians-Universität Munich and Rudolf Bauer of the Institute of Pharmaceutical Science, Department of Pharmacognosists of the Karl-Franzens-Universität Graz. Especially in Germany, there is a long tradition of classifying active herbs and their chemical constituents. For this reason, the monographs on TCM drugs resulting from this work are important features of the scientific activities, as indicated in the cover of this issue and the article by Wagner et al. [3].

TCM is under increasing pressure to show therapeutic efficacy and lack of side effects as well as to improve clinical quality continuously. Therefore, a 'complication screening program' with an effective adverse event reporting system for all used methods in the clinic has been established.

We especially stress the absence of toxins, contamination and adulteration in order to avoid risks for the patients. The article by Melchart et al. [4] describes a model of safety monitoring and risk management in TCM drugs, so that risks can be identified early.

Both Eastern and Western medical systems will benefit from additional TCM approaches, modified according to modern scientific requirements - these objectives are shared by all members of the scientific board.

\section{Acknowledgement}

Anniversaries are golden opportunities to thank all attendants and principle supporters for the clinical, social and scientific contributions in favour of the TCM hospital Bad Kötzting.

By name, many thanks to the whole family Staudinger as the founder, especially Anton Staudinger as the managing director of the hospital, Stefan Hager as medical director as well as all his forerunner for a successful clinical work. We also thank Hildebert Wagner and his team as well as Rudolf Bauer for the pharmaceutical supervision and Wolfgang Weidenhammer, Winfried Banzer, Volker Fischer, Erich Wühr, Stefan Kirchhoff and Wolfram Stör for their scien-

\section{KARGER}

Fax +497614520714
(๑) 2016 S. Karger GmbH, Freiburg

$1661-4119 / 16 / 0237-0001 \$ 39.50 / 0$
Dieter Melchart, MD, PhD

Competence Centre for Complementary Medicine and Naturopathy

Klinikum rechts der Isar, Technische Universität München

Kaiserstrasse 9, 80801 Munich, Germany

dieter.melchart@ mri.tum.de 
tific advice and contribution. Furthermore, many thanks to Erich Wühr for his engagement in organizing teaching courses for TCM many years ago.

The editors are deeply grateful for all the support by the former scientific members Hartmut Heine, Jochen Gleditsch, Walburg Marić-Oehler. Last but not least, sincerely thanks to all authorities in politics, statutory sickness funds, trade associations, world federation of Chinese medicine societies (WFCMS) and the universities, Beijing University of Chinese Medicine, P.R. China and Technical University of Munich, Germany.

\section{References}

1 Hager S, Dai J, Fischer V, et al.: East meets West: synergy through diversity. Forsch Komplementmed 2016; 23(suppl 2):3-7.

2 Weidenhammer W, Melchart D: Quality profiling at the TCM hospital Bad Kötzting - examples from an ongoing systematic patient documentation. Forsch Komplementmed 2016;23(suppl 2):8-15
3 Wagner H, Bauer R, Melchart D: New analytical monographs on TCM herbal drugs for quality proof. Forsch Komplementmed 2016;23(suppl 2):16-20.
4 Melchart D, Hager S, Dai J, Weidenhammer W: Quality control and complication screening program for Chinese medicinal drugs at the first German hospital for Traditional Chinese Medicine - a retrospective analysis. Forsch Komplementmed 2016;23(suppl 2): 21-28. 